\title{
A Framework of Class Attendance System Based on Location Based Service
}

\author{
Qingxiang Wang ${ }^{1, \mathrm{a},{ }^{*}}$ \\ ${ }^{1}$ School of Information, Qilu University of Technology, Jinan, China \\ awqx_sd@sina.com.cn \\ * please mark the corresponding author with an asterisk
}

\section{Keywords: Class Attendance; Location Based Service; Moblie Application; Auxiliary Teaching; Class} Remind;

\begin{abstract}
Class attendance system is widely used in colleges and universities to maintain the students' attendance. In this paper, we proposed a new framework of class attendance system. With the use of base station location services that could quickly determine whether students to class and use the face recognition and dynamic decision to prevent cheating. The system could save the class time and finish the statistics of the class and could realize real-time statistics and feedback quickly. That could provide effective technical support for real time control of the teaching situation for the teachers and the teaching department. It could also save a lot of roll call time and the statistical work after class. With the user authentication methods based on face recognition and dynamic facial features tracking, it could effectively prevent generation, alternative phones, and virtual positioning forging method
\end{abstract}

\section{Introduction}

In recent years, truancy phenomenon of college students was widespread on campus and became the popular disease in colleges and universities which seriously affected the university teaching quality. That also prompted roll call and class attendance became one of the teaching inspection content in many schools. With the development of information, many new technologies are used in class attendance, such as the application of fingerprint attendance system in university management, attendance system based on the large multimedia screen projection. Sichuan University invented "brush face" roll call system. Nanjing Normal University academy launched photograph method for find miss of the student. QR code scan with phone method have presented in Jiangxi Normal University. In addition, the fingerprint and Bluetooth are also used in roll call.

The attendance system has received good effect at the start of execution and curbs the phenomenon of skipping classes of college students. But the regular attendance would occupy the normal teaching time. How to determine the attendance simply and effectively and as far as possible to save class and students' precious time is still a problem that needs to be solved in the teaching.

In this paper, we proposed a new class attendance framework. With the use of base station location services to quickly determine whether students to class and with the use the face recognition and dynamic decision to prevent cheating, that could remind students to attend class and provided the absent statistics to teachers in real time. The method was implemented on cell phones which is convenient for popularization. The main goal of this framework is to remind students and prevent absence from class which can effectively reduce the resistance of the students. And at the same time, the framework is rapid, accurate, anti-cheating and almost do not occupy the class time on the roll call. With those characteristic, that will become a kind of effective means of roll call.

In the second section, we review the related work on class attendance. In the third section, we will introduce our work on class attendance which uses mobile phone and bases on location based service and the last section is the conclusions and future work. 


\section{Related Work}

A lot of works were done around the attendance of campus class. Bennett [1] proposed the result of the examination of the related students' attendance, participation, and explained the relationship of the attendance, participation and performance in higher engineering education module education. The results of the study show that there is a positive and important relationship in class attendance, participation and performance. Gonzalez [2] proposed a mixed strategy for a comprehensive university education example that was for online education on their website and shows the technology for classroom, lab and multimedia.

Gatsheni [3] use the radio frequency to finish the class attendance register. The students had an electronic ID card that could be check automatically with the radio method. The classroom had a check point and if the student entered the classroom, they would be recorded for attendance to the class. Bjelica [4] proposed a similar method. They use the RFID card which can be checked when the check point is nearby. That method can help teacher to control the classes and record the daily teaching activities. But that method would be cheated by agent who takes the card of others. Zhi M [5] also presented the attendance system with RFID. They use the RFID for recording the students' information of class attendance. With the tag ID on the card, they could identify the student automatically and made it quickly in roll call process. But it took a lot of time when entered the classroom and could be cheated with the student who took the card of others. Pham[6] also used the RFID to develop the class attendance manage system in Vietnam.

Liu [7] used the location based service to continuously locate the water pipe supervisors and their work state. Their system is based on GIS and mobile phone. Yi [8] designed a class attendance system based on android. They designed the information manage system with eclipse and sqlite to assist the teacher to manage the information of class attendance. Yamamoto [9] used the student card with a contact type IC and a non-contact type IC to support attendance systems and login system of educational computers. Their system could record the student position information and know the student's activity on the campus.

\section{Class Attendance System Based on Location Based Service}

Location-based services, it is the services to obtain the position Information of mobile terminal users through the telecom operators' radio communication network (GSM, CDMA network) or an external positioning (such as GPS).

Current mobile devices have a variety of location-based services for chosen, such as google map or baidu map. With the current user's location information the unique imei code of mobile phone, we can determine the user's identity. Our work is based on those characteristic.

The system of our class attendance contains two parts. One is running on mobile phone for students. That is made as an app. The other is the service on the server which provides the schedules and records the attendance.

Mobile phone app is divided into the servers and the mobile client for students, and provides web management software for teachers. The user location method is based on combination hot Bssid and the base station. The identification is finished on mobile phone and uploaded the class attendance data to the server. The server collects data and creates summary analysis and record on the disk. Server can also check the position of students regularly, and compare it with the schedule information. If near the class time, the server will send a message to the app and remind the student to attend the class. Students run the software on mobile phone and ensure the network flow.

With those, we can establish the framework of class attendance system. The flow of the system is shown in Fig 1.

In our framework, the system has two servers and a mobile client: one connects the educational administration system which provides the students schedule which include class time and place. 
Mobile client of the attendance system is distributed to students and the client has to connect the network for getting the location.

The flow is listed below:

1. Login app on mobile phone

2. Get the current curriculum schedule of the student

3. Check current time with the schedule class time.

4. If time is not up, goto 5 , else goto 6

5. Remind the student with the left time to the next class. Goto 2 after a delay.

6. Get current location and the class place.

7. Check the current location, if in the right class place, goto 8. Else goto 9.

8. Sign in.

9. Record absence of the student.

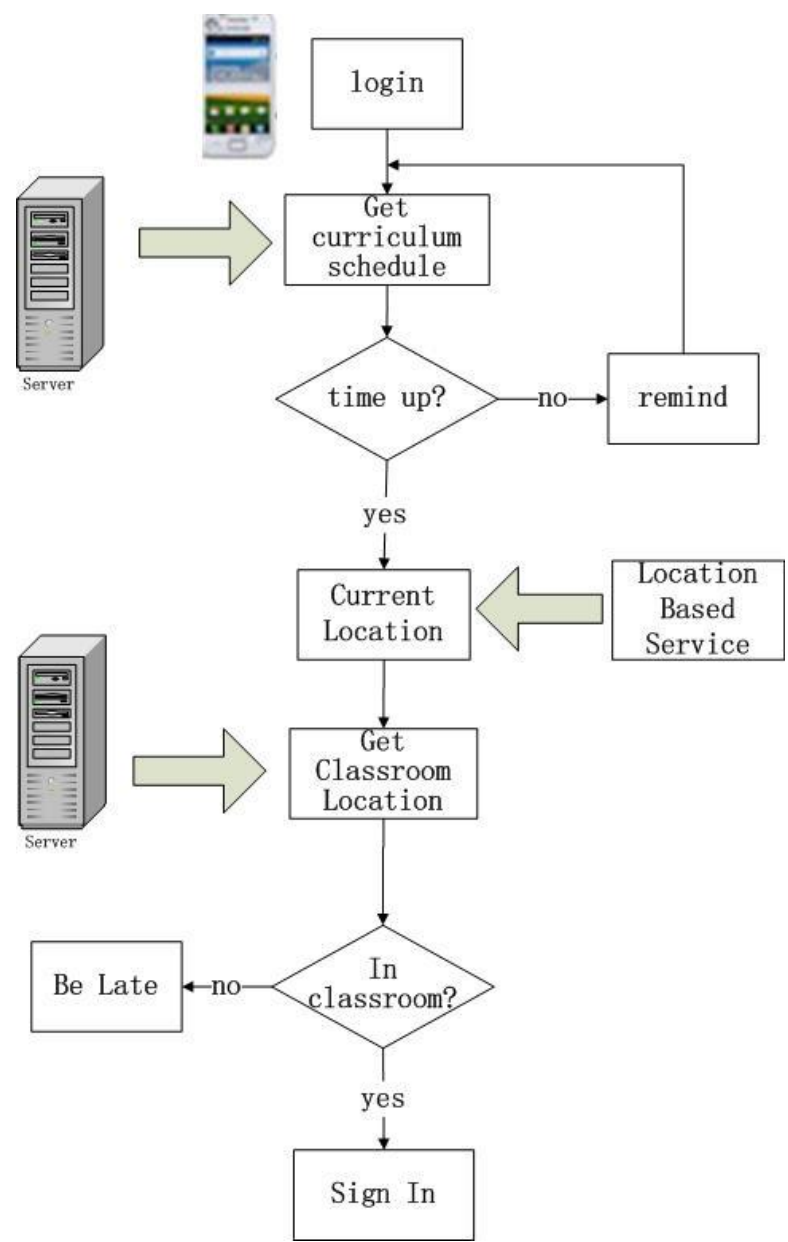

Figure. 1 System flowchart

Another flow is that the teacher can get the statistical information of the attendance in real time. The framework could check the attendance immediately when time is up. That could save more time of class.

In order to avoid the replacer of roll call, we can use a combination of mobile information and authentication mechanism of face recognition [10].

\section{Conclusions and future work}

We proposed a new roll call framework that could finish the attendance statistics immediately at the class beginning. The system could save the class time and finish the statistics of the class and could 
realize real-time statistics and feedback quickly. That could provide effective technical support for real time control of the teaching situation for the teachers and the teaching department. With the current user's location information and the imei code, we can determine the user's identity. The statistics of the class situation can be done quickly and efficiently and educational administration department could control of the actual situation of the various curriculum to the class in real time. It could also save a lot of roll call time and the statistical work after class. With the user authentication methods based on face recognition and dynamic facial features tracking, it could effectively prevent generation, alternative phones, virtual positioning forging method.

\section{Acknowledgement}

This research was supported by the Qilu University of Technology Education Research Project (No. 2013095) and Jinan star science and technology plan (No. 201406004).

\section{References}

[1] T. G. Bennett., S. M. Yalams. Correlates of students' attendance to class, participation and performances in engineering modules. 2013 IEEE Global Engineering Education Conference, (2013) 947-951

[2] J. R. González, K. Cela, R. Cambralla, et al. Information and Communication technologies for a lesser class attendance. Consultado el, 12(2010) 1-14.

[3] B. N. Gatsheni, R. B. Kuriakose and F. Aghdasi. Automating a student class attendance register using radio frequency identification in South Africa. 4th IEEE International Conference on Mechatronics. (2007) 1-5.

[4] O. Bjelica, D. Mijic. Hardware design of a reader device in RFID-based class-attendance system. 20th Telecommunications Forum, TELFOR. (2012) 1068-1071

[5] M Zhi, M. M. Singh. RFID-Enabled Smart Attendance Management System. Future Information Technology-II. Springer Netherlands, (2015) 213-231.

[6] Tuan Dat Pham, W. S. Xu, Z.Y. Xu. Development of RFID-based Class Attendance Information Management System for Universities of Vietnam. Information Technology and Informatization. 4(2013) 98-102

[7] D. Liu, Z. Xie. Corporation personnel management based on GIS and mobile location technology. Diqiu Kexue Zhongguo Dizhi Daxue Xuebao. 5 (2006) 693-698.

[8] G.Z. Yi, J. Xiao and L.Q. Yuan. Design and implementation of class attendance system based on Android platform. Electronic Design Engineering. 22(2015) 1-3.

[9] D. Yamamoto, I. Takumi and H. Matsuo. Location-based social network services employing student cards for university. International Workshop on Location Based Social Networks, LBSN 2009. (2009) 21-24

[10] D. M. Marsico., C. Galdi., M. Nappi., D. Riccio. FIRME: face and iris recognition for mobile engagement. Image and Vision Computing, 12(2014) 1161-1172. 